\title{
Is being a medical educator a lonely business? The essence of social support
}

Joost W van den Berg, ${ }^{1}$ Christel P M Verberg, ${ }^{2}$ Albert J J A Scherpbier, ${ }^{3}$ A Debbie C Jaarsma ${ }^{4}$ \& Kiki M J M H Lombarts ${ }^{1}$

CONTEXT Social support helps prevent burnout and promotes its positive opposite, work engagement. With higher work engagement performance increases. The context-specific aspects of social support for medical educators, in their educator role, are unknown. To help facilitate social support our study describes the essential elements of social support and their meaning for medical educators.

METHODS We held interviews with medical educators purposefully sampled for diverse backgrounds and working circumstances and who spent a considerable amount of time on education. Both clinicians and basic scientists participated. The Pictor technique guided the interviews. Participants were invited to talk about the breadth of social support and elaborate on meaningful experiences. Template analysis was used for a descriptive phenomenological approach.

RESULTS Thirteen medical educators were interviewed. We identified four themes: (i) sources of support and their intent (e.g. a superior with the intent to stimulate personal growth); (ii) the materialisation of support (e.g. sought or offered); (iii) its manifestation (e.g. the act of providing protected time); and (iv) the overarching effect of social support, both in terms of practical effects and the meaning of support. We identified three sorts of meanings of social support for educators. Receiving support could lead to (i) feeling reassured and confident; (ii) feeling encouraged and determined and (iii) a sense of relatedness and acknowledgement of the educator role.

CONCLUSION Support for education comes from a wide range of sources because it is both sought and offered beyond the boundaries of the educational role. The resulting differences in support provided necessitate that educational leaders and policymakers consider the sources available to each educator, connecting educators where necessary. When facilitating or designing social support it is important that the need to feel reassured, encouraged or related is met.

\footnotetext{
${ }^{1}$ Center for Evidence-Based Education Professional Performance Research Group, Academic Medical Center (AMC-UvA), University of Amsterdam, Amsterdam, the Netherlands ${ }^{2}$ ICLON, Leiden University Graduate School of Teaching, Leiden, the Netherlands

${ }^{3}$ Faculty of Health, Medicine and Life Sciences, Maastricht University, Maastricht, the Netherlands
}

\footnotetext{
${ }^{4}$ Center for Education Development and Research in Health Professions, University Medical Center Groningen, University of Groningen, Groningen, the Netherlands

Correspondence: Joost van den Berg, Center for Evidence Based Education, Academic Medical Center (AMC-UvA), University of Amsterdam, Meibergdreef 15, Amsterdam 1105AZ, the Netherlands. Tel: +31 205662 001;

E-mail: j.w.vandenberg@amc.uva.nl
} 


\section{INTRODUCTION}

Social support is essential in becoming and being a medical educator and for creating a sense of community. ${ }^{1-4}$ It is also an important factor in workrelated well-being: a lack of social support has been linked to an increased risk for burnout, ${ }^{5}$ whereas a high level of perceived social support drives work engagement. ${ }^{6}$ Research from other fields provides leads for the facilitation of social support that transcend context, but also indicates that context-specific aspects are important. ${ }^{7-9}$ The current gap in the literature is what social support $i$, what it means and how it comes about in the daily practice of medical educators. To facilitate social support, we need to know what happens in current daily practice both formally and informally. This knowledge may ultimately contribute to the prevention of burnout, fuel work engagement and thus improve the performance of medical educators. ${ }^{5,10}$

Social support is a generic term covering a variety of definitions and operationalisations and used differently throughout studies, settings and measures. ${ }^{7-}$ ${ }^{9}$ A common way of describing social support is by the types of support provided. These include emotional support, such as showing empathy, instrumental support, such as tangible aid, and informational support, such as in problem-solving. ${ }^{7-9}$ Furthermore, companionate support and supporting esteem are known types of support. ${ }^{9}$ In relation to burnout and work engagement specifically, social support is defined as a job resource. ${ }^{11}$ In general, job resources are aspects of work that help reduce demands that arise from work, are functional in achieving work goals, and stimulate personal growth, learning and development. ${ }^{12}$ Social support is a versatile job resource that can fulfill all three functions and this conceptualisation was followed for this study. Social support can help cope with demands because of its positive effect on stress. ${ }^{13,14}$ Social support can either prevent stressful events occurring or alter the perception of such events, so that they become less stressful. ${ }^{7}$ Social support can be an extrinsic motivator in relation to achieving work goals when others provide information or tangible help with work. Furthermore, social support can be an intrinsic motivator for personal growth when it provides a sense of relatedness. ${ }^{6}$ Social support is not solely positive, however. When the provided support does not match the recipient's needs, it can harm self-esteem ${ }^{9,15}$ and autonomy ${ }^{9}$. Furthermore, the absence or perceived absence of social support are distressing factors in themselves. ${ }^{7}$
Conceptualising social support as a job resource emphasises that the social network at work provides support. Social support can additionally be provided by people from outside of work (e.g. family). ${ }^{16}$ What may differ is how the support is provided. Providers from outside of work may focus more on emotional support, whereas colleagues may be better equipped for providing support in the form of helpful information. ${ }^{16}$ This suggests that it is important to take into account the context in which the provider offers support and the relationship between the support provider and support receiver when studying social support.

Medical educators often fulfill multiple, complementary, academic roles and for each role they may belong to communities that exist within and outside of institutions. ${ }^{17}$ Consider, for example, a surgeon educator who is a member of the national association of surgeons, deputy editor for a surgical journal and who also visits educational conferences as programme director of surgical residency training. It is unknown how support for education specifically is experienced in this context of such different roles and communities. Understanding the essential elements of social support experiences and the meaning of social support for the educator role, may give insight into the leads that can be pursued for the facilitation of social support, tailored to this complexity in overlapping and sometimes competing roles and communities.

We conducted an in-depth qualitative analysis of experiences of social support reported by medical educators to answer our two research questions. What are the essential elements of experiences of social support reported by medical educators? What do these experiences mean to medical educators?

\section{METHODS}

\section{Design}

We followed the contextual-constructionist paradigm. ${ }^{18}$ Similar to social constructionism, we acknowledged that there is no single observable truth that can be revealed in research. In social constructionism, the main premise is that people create multiple truths by interacting with other individuals. ${ }^{19}$ Within contextualism, the position is that all knowledge is local, provisional and situation dependent. ${ }^{18}$ As such, we specifically took into account the context of the study and local culture in our analysis. Being interested in describing the lived 
experience of social support and the meaning of social support, we chose a descriptive phenomenological approach. ${ }^{20-22}$ We held individual interviews to focus on in-depth exploration, allowing the participants to talk freely without interference from others. To stimulate the recall of instances of social support we used the Pictor technique. ${ }^{23}$ This method helps participants visualise their social context and gives insight into their social network and possible sources of support. This method has been used with complex social phenomena in health care, such as collaborative working ${ }^{23}$ and lay-care systems. ${ }^{24}$ Participants are given a blank sheet, arrow-shaped post-its in (three) different colours and a pen. They were instructed to use these to depict which people or elements play a role in their social network, with a focus on individuals or groups. We asked them to focus on the social network affecting their educational roles. The participants were instructed to take as much time as they needed and to use a post-it per person or group. They were free to use position, direction and colour as they saw fit. The ensuing Pictor chart directed further interview questions, whereby participants were asked to elaborate on their choices and reasoning for placing (or not placing) specific post-its.

\section{Sample and participants}

This study was conducted at an academic medical centre in the Netherlands, which offers medical education along the entire continuum. We drew our sample from a programme set up there, which aims to connect and advance medical educators. This programme includes educators from different scientific backgrounds and departments and who are involved with coordination, administration or leadership within medical education. They work in both undergraduate and postgraduate education and bring a varied set of educational interests (such as curriculum development, faculty development or professionalism). Many have continued their own development by entering university-led leadership programmes, by obtaining senior university teaching qualifications or by conducting medical educationrelated research. Most are also extensively involved in care provision, research or both. Programme participants are appointed as medical educators for $20 \%$ of their time, excluding time spent on teaching and additional time allotted by departmental heads. The general profile of the programme participants matched our aim to include experienced educators, who teach and were from different backgrounds and departments. We invited all 23 educators from this programme through a direct e-mail invitation because within this group we had no reason to further specify our sample.

\section{Data collection}

To practice the Pictor technique we held a test interview. One researcher (JvdB, a PhD-student, MD and first author of this study) conducted all interviews, which lasted between 45 and 70 minutes. The interviews consisted of four parts. We first asked participants to tell us about their work in education, how long they had worked at our institution and to list any other tasks. Second, we introduced the Pictor technique. ${ }^{23}$ At this point we reiterated that we were interested in how social support occurs and is experienced in daily work and explained the objective of the Pictor technique. A definition and underlying concepts of social support were not presented to the participant at this point, to allow the participant to focus freely on persons they felt supported or unsupported by and incidences during which they felt supported or unsupported. Third, they were asked to elaborate on their entire Pictor chart and reflect on whether their current, displayed situation was an ideal one. Lastly, the participants were asked to elaborate in depth on one to three examples provided during their elaboration of the Pictor chart to fully explore lived experiences of social support beyond mere factual explanations as given during the earlier interview stages. Afterwards the participants were e-mailed a photo of their Pictor chart and asked if new topics or examples had arisen and if they had any other comments and additions. No one wished to make any comments or additions.

\section{Data analysis}

Each interview was audio-recorded, transcribed verbatim and anonymised. The qualitative data analysis software MaxQDA Version 11 (Verbi GmbH, Berlin, Germany) was used to support the template analysis stage. Notations additionally were made with a pen on paper manuscripts and if necessary transferred to the analysis software. Analysis started directly after the first interview and continued simultaneously with data collection. The analyses did not have an effect on participant selection or the content of subsequent interviews.

We used the template analysis method ${ }^{25}$ to apply descriptive phenomenology. ${ }^{20-22}$ There are several core steps. First is to (try to) set aside one's preconceptions - bracketing. Second is to identify and analyse those parts of the interview wherein the 
participants speak about their experiences. The third step involves finding commonalities between participants and intuiting the findings. The fourth step is describing the findings. ${ }^{21,22}$ After attaching meanings to participants' statements about their experiences, these are clustered into themes. At this stage the template analysis was most prominently used. Table 1 provides a brief summary of the different steps in the data collection and the analysis conducted on each step. We chose a broad set of distinguishable support types for our initial template to ensure many variations in support were acknowledged during analysis, while remaining open to new themes if these five did not suit an experience. The initial analysis was carried out on segments of several lines covering the participant's description of a situation, person or perception of support. First, the type of support was identified by seeking indicative words and expressions and subsequently characteristics would be coded. The first three interviews were independently analysed by two authors (JvdB and $\mathrm{CV})$.

During the initial analyses JvdB found the secondlevel codes more informative than applying type of support as a label, in understanding the essence of support in general. The recurring second-level codes were: (i) source of support and aim of the provider, (ii) characteristics of support, (iii) the manner in which the support was provided and (iv) adequacy and effect of support. One author (CV) then independently coded the first three interviews based on these codes. To further develop the template, the fourth to the seventh interviews were discussed based on the first-level codes by the entire research team. The first-level codes were slightly renamed to better fit underlying codes, but the structure remained the same. Through further discussion only minor changes were made to the second and third-level codes in the current template. After the eighth interview no more changes were made to the template and the resultant template was used to help identify surprising and exemplary occurrences of social support. All participants were sent our final results section and were asked to trace the results back to their own experiences. Some made minor suggestions regarding our choice of words, which were incorporated in the description of the results.

\section{Ethical considerations}

Ethical approval was obtained through the Netherlands Association for Medical Education Ethical Review Board under dossier number 540.
Table 1 Summary of data collection and data analysis; regular text describes the steps of the interview and analysis and italics indicate the content of each step

\section{Data collection/ \\ Interview set up}

Introduction

Background, roles

and tasks

Pictor chart creation

Explanation and

creation of

overview without

interference

Elaboration of Pictor chart social support and brief examples

Detailed description of one or more occurrences of social support
Insight into breadth of
Data analysis

Transcribed without additional analysis

Template analysis

Specific coding on Pictor chart as part of (i) source of support (see below)

Template analysis

Initial coding of support type: emotional, instrumental, informational, companionate and supporting esteem

Final first-level codes: (i) source of support and aim of the provider,

(ii) characteristics of support,

(iii) the manner in which the support was provided and (iv) adequacy and effect of support

Template analysis and collection of rich descriptions

Included in the template analysis and additional collection and analysis of significant statements on the meaning of social support for the participant
RESULTS

We held 13 interviews; the participant details are listed in Table 2. To ensure anonymity, the participant details are presented as approximations. The career phase may differ from employment at the current institution when participants recently joined the institution.

We were able to identify four themes: three covering the essential elements of social support and the fourth covering the overarching effect and adequacy 
Table 2 Participant details

\begin{tabular}{|c|c|c|c|c|c|}
\hline No. & $\begin{array}{l}\text { Pseudonym } \\
\text { (gender) }\end{array}$ & Background & $\begin{array}{l}\text { Career phase } \\
\text { (including at } \\
\text { any other } \\
\text { institutions) }\end{array}$ & $\begin{array}{l}\text { Employment at } \\
\text { current } \\
\text { institution }\end{array}$ & Overall task profile \\
\hline 1 & Charles (M) & Basic science & Mid-late & $\begin{array}{l}\text { More than } \\
20 \text { years }\end{array}$ & $\begin{array}{l}\text { A full-time educator. Chair of several educational committees } \\
\text { and projects as well as member of several other committees, } \\
\text { both within and outside of the institution. Provides around } \\
100 \text { hours yearly of undergraduate teaching }\end{array}$ \\
\hline 2 & Annie* (F) & Medicine & Early-mid & $\begin{array}{l}\text { More than } \\
5 \text { years }\end{array}$ & $\begin{array}{l}\text { Primarily works in patient care, including administrative tasks } \\
\text { and projects related to patient care, in addition to the } \\
\text { educational work. Recently more directly involved with } \\
\text { residency training and involved with undergraduate teaching } \\
\text { for somewhat longer }\end{array}$ \\
\hline 3 & Diane $(F)$ & Medicine & Mid & $\begin{array}{l}\text { Approximately } \\
10 \text { years }\end{array}$ & $\begin{array}{l}\text { Described an equal amount of time spent in care, research and } \\
\text { education (which previously was primarily patient care). } \\
\text { Described diverse tasks, including teaching outside of the } \\
\text { institution, and leads multiple projects }\end{array}$ \\
\hline 4 & Ellen (F) & Basic science & Mid & $\begin{array}{l}\text { Approximately } \\
15 \text { years }\end{array}$ & $\begin{array}{l}\text { Equal combination of laboratory work and education in the } \\
\text { broadest sense. Regular teaching of a wide range of students } \\
\text { from different institutions as well as leadership and } \\
\text { administrative positions }\end{array}$ \\
\hline 7 & Florence (F) & Medicine & Mid-late & $\begin{array}{l}\text { More than } \\
15 \text { years }\end{array}$ & $\begin{array}{l}\text { Spends time mostly in education with some time in research. } \\
\text { Many administrative tasks in education as well as member of } \\
\text { several committees. Also involved in undergraduate teaching }\end{array}$ \\
\hline 5 & Gemma (F) & Basic science & Mid & $\begin{array}{l}\text { More than } \\
15 \text { years }\end{array}$ & $\begin{array}{l}\text { Described some administrative tasks, but mostly teaching and } \\
\text { education. Membership of several projects, including leadership } \\
\text { positions. Estimated about } 1 \text { day per week on average spent on } \\
\text { undergraduate teaching }\end{array}$ \\
\hline 6 & Harold (M) & Medicine & Mid-late & $\begin{array}{l}\text { More than } \\
25 \text { years }\end{array}$ & $\begin{array}{l}\text { Is not employed at the institution full time, but that time is } \\
\text { mostly spent on education. Involved with teaching, } \\
\text { development of education and research in education }\end{array}$ \\
\hline 8 & $\operatorname{Ivan}(\mathrm{M})$ & Medicine & Mid-late & $\begin{array}{l}\text { More than } \\
25 \text { years }\end{array}$ & $\begin{array}{l}\text { Combines patient care with research and several educational } \\
\text { projects as well as undergraduate teaching and clinical } \\
\text { teaching. Several leadership positions and administrative roles }\end{array}$ \\
\hline 9 & Bob* (M) & Medicine & Mid & $\begin{array}{l}\text { Approximately } \\
15 \text { years }\end{array}$ & $\begin{array}{l}\text { Describes an equal division of time between patient care, } \\
\text { teaching and clinical teaching, with a minor involvement in } \\
\text { research. Teaching within and outside of institution. Member } \\
\text { of several projects and in leadership positions }\end{array}$ \\
\hline 10 & Joanna (F) & Medicine & Mid & $\begin{array}{l}\text { More than } \\
5 \text { years }\end{array}$ & $\begin{array}{l}\text { Primarily works in patient care, with half her time divided } \\
\text { between education and research. Involved in undergraduate } \\
\text { teaching and in residency training. Is in leadership positions } \\
\text { and member of several committees }\end{array}$ \\
\hline 11 & Kyle (M) & Basic science & Late & $\begin{array}{c}\text { More than } \\
10 \text { years }\end{array}$ & $\begin{array}{l}\text { Almost full-time in education, with some administrative tasks. } \\
\text { Involved in both undergraduate teaching and residency } \\
\text { training. Member or chair of several committees and projects, } \\
\text { both within and outside of the institution }\end{array}$ \\
\hline
\end{tabular}


Table 2 (Continued)

\begin{tabular}{|c|c|c|c|c|c|}
\hline No. & $\begin{array}{l}\text { Pseudonym } \\
\text { (gender) }\end{array}$ & Background & $\begin{array}{l}\text { Career phase } \\
\text { (including at } \\
\text { any other } \\
\text { institutions) }\end{array}$ & $\begin{array}{l}\text { Employment at } \\
\text { current } \\
\text { institution }\end{array}$ & Overall task profile \\
\hline 12 & Leo (M) & Basic science & Mid & $\begin{array}{l}\text { Approximately } \\
10 \text { years }\end{array}$ & $\begin{array}{l}\text { Mostly education with only minor administrative tasks. Has } \\
\text { leadership positions within education as well as membership } \\
\text { of several committees. Involved in undergraduate teaching }\end{array}$ \\
\hline 13 & Mary (F) & Medicine & Mid & $\begin{array}{l}\text { More than } \\
5 \text { years }\end{array}$ & $\begin{array}{l}\text { Combines patient care with research and education, with } \\
\text { patient care taking priority. Involved with both undergraduate } \\
\text { education and residency training. } \\
\text { Has leadership positions as well as committee and project } \\
\text { membership, within and outside of the institution }\end{array}$ \\
\hline
\end{tabular}

Pseudonyms were assigned to each participant and will be used to reference participant citations in the results section. Time of employment at the current institution provides a sense of how long the participant has had to build up a social network within the institution. The overall task profile provides a sense of what their full workload looks like. There is some lack of detail in both columns and we do not list specific departments in order to ensure anonymity is retained.

*Annie and Bob, whose Pictor charts are shown.

of social support. The three essential elements were: (i) the source of support and intent of the provider, (ii) the materialisation of support and (iii) the manifestation of support. The overarching effect and adequacy, the fourth theme, encompasses both the practical and tangible effects as well as the meaning of support to medical educators. In the results section we will describe the relation between these four themes by first describing the Pictor charts and sources, then the materialisation and manifestation of support, and we end the results section by describing the tangible effects and different meanings of social support.

To illustrate our findings with citations, we drew from all interviews but did not necessarily include all participants. In addition, we use the Pictor charts from two participants to illustrate the breadth of sources of support and perceptions on overall support. We chose these participants because both participants gave examples illustrating multiple themes, and the Pictor charts show contrasting examples of overall perceptions of social support. For ease of reading, all cases were given fictionalised names.

\section{General findings and commonalities among Pictor charts}

The common way for participants to create their Pictor chart was to use directionality of arrows and distance between arrows to visualise their support systems. Colour was rarely used as an indicator. We observed differences between charts in the extent to which arrows were connected with other arrows. On one end of the spectrum is extensive connectedness (Fig. 1), containing few unrelated elements. The other end of this spectrum would be absence of connectedness (Fig. 2). Bob explained this as: 'The problem is of course, and that's sort of how doctors arrange their education, we do a lot of it alone and that is what we are used to when we work with patients, as then we are also alone and only when [we face problems] do we consult others'. However, no particular relationship between connectedness on the chart and experiences with support arose from our analyses. Figure 2 represents the only participant, Bob, who chose to elaborate on a negative experience at the end of the interview. Because his other experiences included positive experiences and other participants with relatively unconnected systems also spoke of positive experiences, we found no reason to assume a relationship between support experiences and interconnectedness of the system at large.

\section{Sources of support}

Several recurring sources of support were identified; these are listed in Table 3 and include examples used by multiple participants. We grouped the 


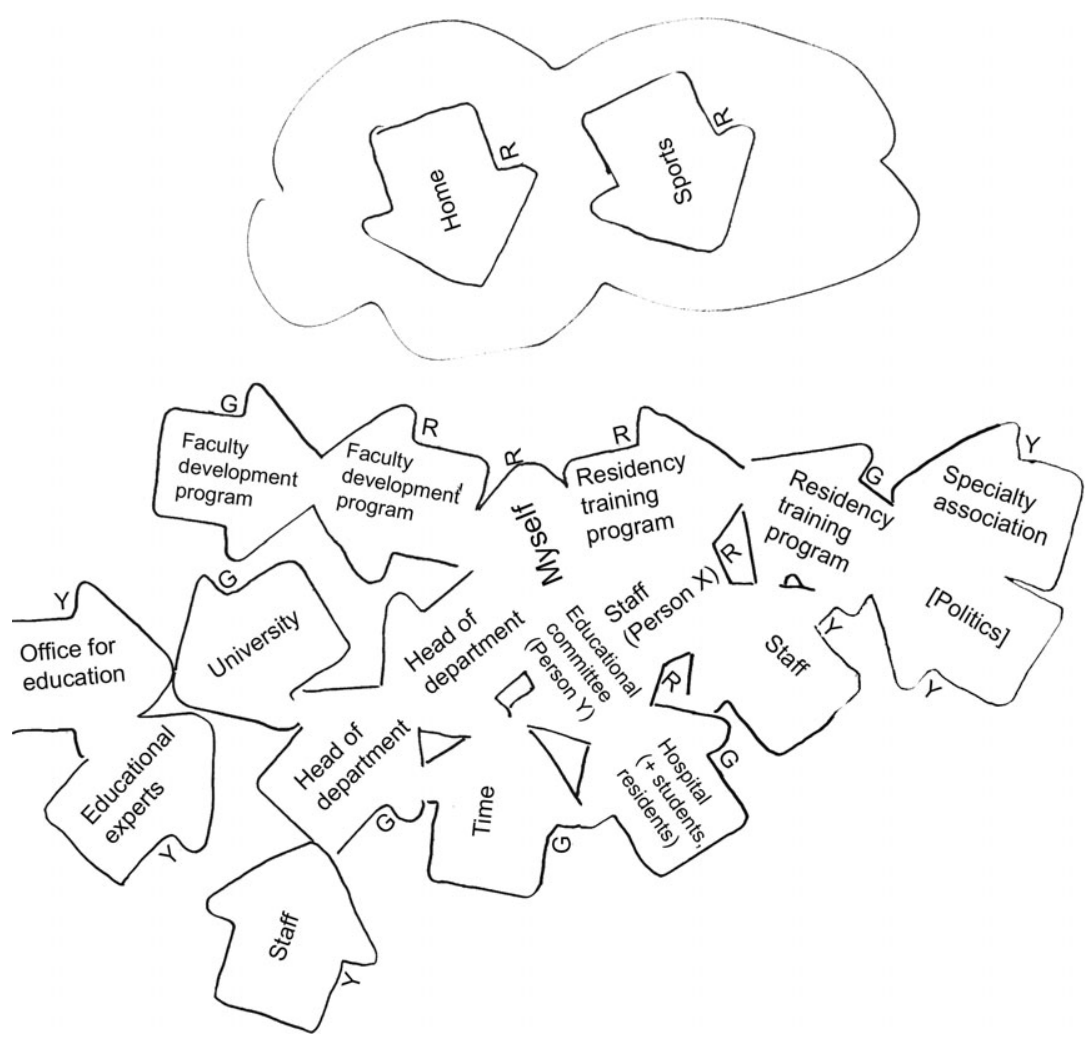

Figure 1 Annie's social network. She reflected: 'Indirectly, there are things behind [other things] which affect you, but you can't get a grip on [...] It feels like a circle from which I receive and to which I give'

sources based on their physical location during analysis, in line with how most participants grouped the sources on their charts where applicable. Apart from the direct superior, often the head of the department, no other specific person or group was mentioned as crucial overall. The importance of particular sources was both individual as well as situational. An example of the individuality is 'home' (e.g. partner or children): indispensable to some; others mentioned receiving no specific support for their educational work from outside of work. The situation often relates to support for specific tasks: if a course was co-directed with another educator, this co-director could be indispensable in the case of marking the course exams. However, this distinction is mostly related to the tangible effects of support. For the eventual meaning of support, all of the sources appeared equal.

\section{Intent of the support provider}

The perceived intent of the provider affects the perception of the support. One participant, Mary, specifically stated that it was her belief that support is only provided if it also benefits the provider but that such acts are not true support. She concluded that she rarely received support, making education to her something of a lonely business. Mary illustrated her feeling by saying: 'It almost never happens that someone walks up to you to say "How great of you to give four lectures this year". She then explained that this never happens because the provider doesn't have anything to gain by showing such recognition. For others, the supportive effect would remain but the intent of the provider could lessen or strengthen the effect. For example, a decision of the departmental head to allocate protected time for education was perceived as less supportive when this was primarily done for the greater good of the department (e.g. the educational obligations) rather than so the educator could use such time for personal growth. Annie had experiences with both such occasions and therefore listed the head of the department twice and ambiguously.

\section{Materialisation of support}

How support was provided varied from only when perceived as available, to sought support, to offered and even imposed support. The materialisation of support affects the perception of support. An example of sought support was illustrated by Annie. She 

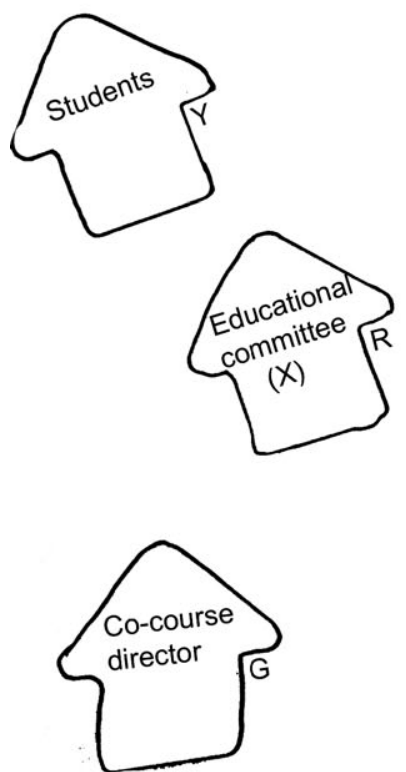
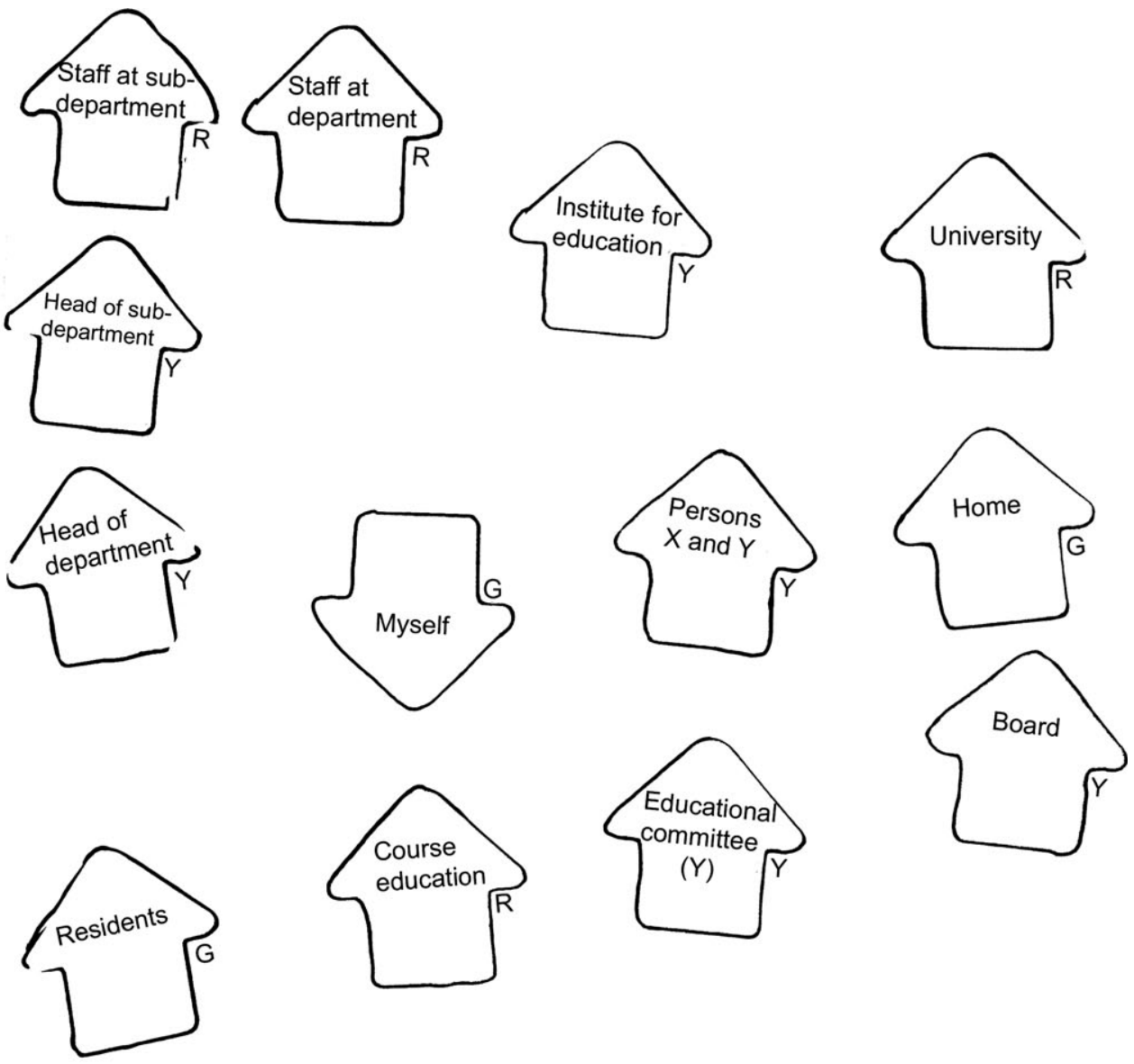

Figure 2 Bob's social network. Halfway through the interview, Bob reflected: 'Actually, this also shows nicely how it is with education because all the [post-its] are [put down] randomly and that's real life for me. I have all these actors who all want something and there's no structure at all'

Table 3 Examples of recurring sources of support

\begin{tabular}{|c|c|c|}
\hline Group & Subgroup & Examples \\
\hline \multirow[t]{3}{*}{$\begin{array}{l}\text { Within } \\
\text { work }\end{array}$} & $\begin{array}{l}\text { Within primary } \\
\text { department }\end{array}$ & $\begin{array}{l}\text { Head of department, colleagues, } \\
\text { secretariats, residents }\end{array}$ \\
\hline & $\begin{array}{l}\text { Within the } \\
\text { institution at } \\
\text { large }\end{array}$ & $\begin{array}{l}\text { Board of directors, other } \\
\text { educators, educational experts, } \\
\text { students }\end{array}$ \\
\hline & $\begin{array}{l}\text { Outside the } \\
\text { institution }\end{array}$ & $\begin{array}{l}\text { Members of national } \\
\text { committees, other universities }\end{array}$ \\
\hline $\begin{array}{l}\text { Outside } \\
\text { of work }\end{array}$ & & $\begin{array}{l}\text { Home, family, friends, others } \\
\text { such as sports }\end{array}$ \\
\hline
\end{tabular}

had had multiple experiences with social support from the head of her department. She once was in acute need of advice after having denied a candidate residency training in an interview. She needed help with handling the candidate's reaction and literally found an open door and immediate support when she sought it. This had a very strong and positive effect on her, which she described as feeling 'personal growth' in that role. In Bob's example, the co-director for the course within the medical curriculum is an example of support perceived as available: 'He is not going to come to me and [say] what can I do now and how can I help, but I can always call on him'. Knowing the co-director was available thus reassured him.

\section{Adverse effects}

When support was imposed or when support was sought but denied the effect could be adverse. As Gemma explained:

'Those two individuals are really adverse. [...] They don't stand by agreements, aren't honest, I don't perceive them as honest to say so. You agree to something together and then they don't 
stick to their words and then they pass the buck and I perceive that as annoying'.

For Gemma, the broken promises evoked negative feelings, rather than feeling impartial. The ambiguity of imposed support was described by Annie through how directions and guidelines helped her find her way in a new educational task at first, whereas later she would find such support restrictive. The person who handed her these guidelines was perceived as supportive at first, but eventually she felt her autonomy was curbed.

\section{Manifestation of support}

Social support manifested itself in a variety of ways. Through verbal support, acts (including decisions and orders) and as an atmosphere. Continuing the earlier example in which Annie sought (and found) support, the manifestation of the support was helpful advice that she could then apply to the problem at hand. By contrast, an example of verbal support, without practical implications, was given by Ivan (elaborating on an email conversation): 'I received an email from him: "totally agree, I stand behind you, you're doing enough already"'. This was said without further action taken by the provider or receiver. However, especially when verbal support should lead to an act or decision but did not, the verbal support would lose its positive effect. As Diane explained: 'And that has been promised for three years now and for three years nothing happened. [...] I do not find that supportive'.

Support from groups was often described in terms of the - supportive - atmosphere created by colleagues and not by acts or verbal support.

\section{Effect and adequacy}

The effect of receiving support is twofold. First, the supportive act could lead to changes (or perceived changes) in the task and work environment and, second, it could affect the support receiver personally by having a meaning to the receiver. The following quote highlights the duality of the effects. This physician-educator, Joanna, is a member of an educational committee, from which she occasionally receives support. Both the practical information she receives and a certain amount of respect, simply help her to do her work, the practical effect. In addition, she also related the perceived respect as acknowledgement and justification of her work, the meaning.
'[The educational committee] makes my work at my department much easier, because I now understand better what is expected from a clinical teacher and I can implement initiatives with more ease [...] but it is not only the knowledge I gather there, which is easy to get by, and the background information, but also ... I wouldn't exactly call it prestige, it's the respect I receive at my department that [makes] my work [easier to do].'

However, some support is just helpful and nothing more.

Florence: 'They helped bring some structure to our quality assurance, something we already did but not so... explicitly. Well, this just helps, a lot $[\ldots]$ in making our education better'.

The participant did not attach any meaning to this particular instance of support. However, all sorts of support could carry a deeper meaning for our participants.

\section{Meaning of social support for medical educators}

We found three types of meaning of social support for medical educators: (i) reassurance and confidence, (ii) encouragement and determination and (iii) relatedness and acknowledgement of educational work.

\section{Reassurance and confidence}

In Dutch, the word used for both 'trust' and 'confidence' is the same ('vertrouwen'). The use of this word occurred often in reaction to an event or issue for which support was received and participants subsequently felt reassured. In other words, a suboptimal situation was improved by the support. When participants talked about receiving such support, it would often mean that they felt everything would be alright.

Returning to the advice Annie received on handling the candidate's reaction to her rejection:

'He said: "Yes, I've had that happen to me once. It usually helps to arrange a second interview" [...] and [then] the second interview was fine, there was nothing wrong. [...] And now I'll say to myself [if it happens] next time: "Ah yes, well, everything will run well"'.

The first part of this quotation is about reassurance. The second part of the citation carries a more long- 
term meaning and the participant concluded she had grown as an educator after this had happened.

Another example was when someone from a different educational department offered to take over a chore from Diane: 'That kind of support from people ... that one, indeed, can delegate things with confidence. That is very pleasant'. In her words, this was a minor thing, yet it still carried a lingering effect as a meaningful act of support.

\section{Encouragement and determination}

Characteristic of encouragement is that participants were not simply being inspired but they were subsequently also acting upon this. This more often represented a fine situation made even better through the support. During some interviews, participants would intensively use positive words like 'enthusiasm', 'positive', 'inspiring' and 'stimulating'. Gemma even remarked on working with a few enthusiastic educationalists from another department: 'The recognition, knowing you're being listened to, humor, everyone bringing something of their own. That makes you grow wings'. She continued by saying that this feeling enabled her to work on ideas even outside regular working hours.

Several examples within this theme were from participants who had held an idea for an educational innovation for months or years. Only once they had talked to someone who was a role model or new at the institute would the enthusiastic reaction be the final push towards activation. Often, this support was only verbal and not related to tangible support. To illustrate, Harold said about being given the feeling he had a promising idea:

'That he supports ... your own desire to apply and that he says: do it! Do it. I think that, had he been entirely negative, if I had been given a negative feeling I would have reconsidered. I might still have applied [for the position] but it would've been more difficult.'

This last example is about a conversation between someone higher up in the hierarchy who had no say in this particular application, yet his positive reaction enabled the participant to move on.

We found that tangible supportive acts can be especially encouraging in addition to being practically helpful. Acts or events such as arranging regular meetings, being introduced to other people or regular feedback would both enable and encourage participants to carry out ideas.

\section{Relatedness and acknowledgement of educational work}

Relatedness includes both short-term feelings and a more overall feeling (e.g. an overall sense of purpose). This overall feeling includes examples where the participant would explicitly attach the meaning of 'not feeling alone' to the support, which we interpreted as being about 'relatedness' and a 'sense of belonging'.

Examples of feeling connected, rather than related, in the short term included expressions from the support provider such as 'I agree with you, I'm with you on this', which Ivan received in an e-mail. The meaning attached by the participant was literally that he felt he wasn't left on his own: 'they immediately help me take a stance and then I feel I'm not on my own in this issue'. In addition to verbal support, several participants noted that they had persons around them they could (strongly) rely on when something needed to get done. Ellen: 'She always pulls me up when I sort of [laughs] had enough or whatever, you know? Well, sometimes it isn't so bad but at other times it's a big job. One that takes two to do'. This last example was about a single point in time, relating to the task of marking exams.

Similar expressions were used to indicate a more overall feeling as well. These were characterised by 'together' in addition to the meaning of 'not feeling alone'. Many participants would use words like 'together' and 'cooperation' repeatedly within an example. One particular meaning was attached by multiple participants, which referred to 'becoming human to each other' rather than just colleagues. This evoked a sense of solidarity and lowered the barrier to approaching someone for help.

As Gemma explained what this meant, she told about regularly commuting with someone from the educational department (not her own). This had led at first to discussing work-related issues but later also to sharing personal information.

'I find it so nice that we also talk what one could call personal matters. Indeed. You get to know someone on a different level. [...] It makes everything so much more accessible. [...] What that means? Well, a bit of accessibility, you know, becoming, simply, human to each other. I find that very important, [...] You know, when it rains 
that [he] says "leave your bike, I'll drop you off at home".'

Furthermore, this theme is not only about relatedness to others but also the acknowledgement of the educational role, a feeling their work in education matters. In addition to the example about feeling respected, under 'Effect and adequacy', Gemma stated this meaning matter-of-factly, when asked about being able to drop in on short notice and being listened to, as: 'You feel taken seriously. Period. [...] You matter and that you are able to, simply, contribute to what happens here.'

Whereas all other participants chose to elaborate on a positive experience with social support, Bob spoke about lack of support. By contrast with the positive experiences, the word that characterised his elaboration was 'alone'. He often felt 'alone' in education and in solving issues related to his educational task.

\section{DISCUSSION}

This study sought to answer two research questions. What are the essential elements of experiences of social support reported by medical educators? What do these experiences mean to medical educators? There are three essential elements of support: (i) the source of support and intent of the provider, (ii) the materialisation of support and (iii) the manifestation of support. Sources are reported from across roles and tasks. Being a medical educator is thus not a lonely business per se, as some participants, such as Mary and Bob, did experience at times. Receiving support, in answer to the second question, could lead to feeling reassured and confident, encouraged and determined and to a sense of relatedness and acknowledgement of working in medical education.

In our introduction we described that medical educators are at risk of not feeling part of any community - the clinical, research or educational community. ${ }^{17}$ Yet, our results suggest medical educators may still find support in education from members of all these communities. There are two explanations for this finding, relating to the importance of specific relationships and to the theory of communities of practice.

One specific and important relationship, unrelated to any community, is that with the heads of departments. Their importance probably arises from their departmental responsibility for patient care, research and education; therefore they often provide support for all roles. That additional sources of support were equally sought and found beyond the boundaries of the educational task resonates with previous research showing antecedents of work engagement may overlap between roles. ${ }^{26}$ This overlap appears positive for receiving social support.

Communities of Practice have surfaced in faculty development literature as something to pursue. ${ }^{27-30}$ Although it was not our intention to evaluate the programme from which we drew our sample, as a context it may help explain our findings related to communities. A community (of practice) requires a common goal and is often bound by informal relationships. ${ }^{31}$ As we described, our participants came from different departments, each bringing their own interest, and thus may not share the necessary meaningful activities. ${ }^{32}$ 'Medical education' as a broad topic apparently is an insufficient common goal to form a community around. Our results suggest the opposite. By seeking or finding support from specific individuals for their particular work in education, as opposed to their general work in education, medical educators each form the centre of their own (small) community of practice and draw from their network across roles and tasks. Social support is then not a result of a community, but the start.

We add to the literature on well-being in several ways. Seeking support is a strategy within job crafting, the act of making changes in the work environment and part of the work engagement literature. ${ }^{33}$ Our results suggest that educators may seek support beyond the boundaries of their roles, which has not previously been described. Perhaps unsurprisingly, the qualitative descriptions of our participants align with the previously quantified positive effect on perceived well-being and the possible negative effect of absence of support. ${ }^{6}$ The finding that imposed support may lead to negative effects on self-esteem and perceived autonomy is reiterated. ${ }^{9,15}$ However, we also show that imposed support may be especially helpful for new tasks. Our last addition is to the mechanism through which social support functions as a job resource, until now described in terms of its effect on feeling related, ${ }^{6}$ based on the self-determination theory. ${ }^{34}$ The self-determination theory (SDT) additionally describes the feelings of competence and autonomy as the basic psychological needs that drive motivation. Our finding that social support may also lead to feeling reassured and confident and to feeling encouraged and determined may be explained by the competence component of the 
SDT: restoration or strengthening of the feeling of competence makes an act supportive.

\section{Strengths, limitations, reflexivity and transferability}

This study builds upon previous applications of the Pictor technique in research on collaborative working and social connections in health care ${ }^{23,24}$ by focusing on educational work in health care specifically. It invited the participants to elaborate on the full breadth of support rather than what comes to mind first. This helped gain insight into a wide variety of supportive experiences and was found to be beneficial to answering both research questions. Additionally, our participants noted it was a fun exercise to conduct. Although this study provides a general overview of social support for education, we feel our results provide suggestions for practice for both individual educators and leaders and policymakers in other fields as well.

The author who conducted the interviews (JvdB) was well embedded in the local situation, allowing for quick understanding of the context by the participants. This is both a strong point and a pitfall. We attempted to avoid jumping to conclusions by checking any interpretations regularly with participants during the interview. Although we had no assumptions on the satisfaction of participants with the level of support received, field notes made by $\mathrm{JvdB}$ indicate a positive atmosphere during most interviews.

This study made us reflect on to what extent we studied leadership or social interactions in general, rather than social support. Our participants clearly spoke of support and supportive acts rather than 'interaction'. They distinguished between administrative decisions and support and were able to explain when such occurrences felt supportive. We feel it could be considered a limitation that we did not more strongly pursue the distinction between leadership and support. Our results suggest there is an overlap, but studying leadership was not part of our aim.

The main author $(\mathrm{JvdB})$ of this study was trained as an MD and before commencing his PhD had only learned the positivist perspective on research. During his $\mathrm{PhD}$ he familiarised himself with the different paradigms, epistemologies and qualitative research methods. He believes one can choose a paradigm and apply an epistemology, but it takes effort to conduct research from such a chosen stance. For this particular study we presumed there is no single observable truth when it comes to human interaction, but setting aside preconceptions is not easily done. An important preconception that did not arise from the literature was that people are naturally inclined towards helpful behaviour and this was indeed challenged by some participants' expressions. The research team consisted of researchers from various backgrounds, including medicine and educational sciences. However, all have long worked and published within the (medical) educational field and were familiar with this type of research.

The struggle between acknowledging what one's preconceptions are and, by contrast, trying to set them aside, is prominent in our research. As we tried to attach meaning to the participants' statements in an open way, we subsequently felt uncomfortable with the a priori themes we had defined for clustering the statements and meanings. When we let go of these a priori themes and moved the attached meanings to prominence, the analysis felt more natural and closer to the data at hand.

Lastly, we feel our findings are transferable to other contexts but culture should be taken into account. The difficulty of dividing time between patient care, education and research appears universal. However, the Netherlands has been described as an individualistic society. ${ }^{35}$ Our participants appeared to have many sources of support and to receive support adequately, but in less individualistic cultures the provision of support may be even more common.

\section{Implications for practice and future research}

Superiors, directors and deans should actively use their powerful positions in providing support. Seemingly little things, such as paying attention and showing enthusiasm, are important in feeling supported. More than words, promises of taking action need to be kept where possible. It does seem necessary that the support provider and receiver share some common ground, whether it is through their clinical or research work, their educational task or just shared interests. This common ground must be more specific than medical education at large and may thus involve smaller topics such as undergraduate or postgraduate training, assessment or professionalism. This additionally raises the question of whether, within one medical or research department, an educational community can arise if the educators there do not share common goals within education.

For individual educators, it is important to take the matter into one's own hands. Actively shaping one's 
work has been associated with increased well-being and performance and seeking support may be a first step. $^{36,37}$

The concept of mentorship might be explored both by institutions, by setting up mentorship programmes, and individuals, by seeking a mentor themselves. Mentorship has been found to increase personal and professional growth ${ }^{38}$ and could provide a reliable and continuous source of support, especially when the mentor shares an interest in education with the mentee.

We suggest that future research should focus on two topics regarding providing support. First, investigating the optimal circumstances for others to provide support. Second, our participants very rarely described occurrences of giving support or reciprocity in support, but providing support is known to be beneficial to well-being. ${ }^{39}$ Future research could thus provide a more detailed description of what it means to provide support.

Our study indicates that social support is an individual matter. However, there appeared to be commonality in the importance of some sources. To find out whether this finding is generalisable and to identify truly crucial providers of support, a quantitative approach may be necessary.

Although recent studies have shown that seeking social resources benefits performance in health care, ${ }^{37}$ it remains to be studied whether seeking social support directly increases performance in education.

\section{CONCLUSIONS}

In considering or facilitating social support, the source, manifestation and materialisation of support should be kept in mind to understand the effect of instances of social support. For overall perceptions of support, it appears more important that medical educators find supportive individuals rather than an institute-wide educational community. Support for education is both offered and sought beyond the boundaries of the educational role. Meaningful support may lead to feeling reassured, encouraged and connected.

Contributors: JvdB was the initiator of this study, drafting the study design and obtaining ethical approval. All authors contributed to the study design. JvdB conducted the interviews and led the process of analysis and interpretation of the data. CV participated in the analysis through additional coding. CV, AS, DJ and KL additionally contributed to interpretation of the data through discussion of and reflection on the analysis. JvdB wrote all the drafts, which were revised with input from all authors. All authors contributed to the revision of the paper for critically important intellectual content. All authors approved the final manuscript for publication. All authors agree to be accountable for all aspects of the work in ensuring that questions related to the accuracy or integrity of any part of the work are appropriately investigated and resolved.

Acknowledgements: We thank Irene Slootweg PhD for her contributions to the design and analysis sections of this study.

Funding: none.

Conflicts of interest: there are no competing interests to report.

Ethical approval: ethical approval was obtained through the Netherlands Association for Medical Education Ethical Review Board under dossier number 540.

\section{REFERENCES}

1 Bartle E, Thistlethwaite J. Becoming a medical educator: motivation, socialisation and navigation. BMC Med Educ 2014;14 (1):110.

2 Glew RH, Russell JC. The importance of community in academic health centers. Teach Learn Med 2013;25 (3):272-4.

3 Sherbino J, Snell L, Dath D, Dojeiji S, Abbott C, Frank JR. A national clinician-educator program: a model of an effective community of practice. Med Educ Online 2010;15:1-8.

4 Lown BA, Newman LR, Hatem CJ. The personal and professional impact of a fellowship in medical education. Acad Med 2009;84 (8):1089-97.

5 Maslach C, Schaufeli WB, Leiter MP. Job burnout. Annu Rev Psychol. 2001;52:397-422.

6 Bakker AB. An evidence-based model of work engagement. Curr Dir Psychol Sci 2011;20 (4):265-9.

7 Barrera M. Distinctions between social support concepts, measures, and models. Am J Community Psychol 1986;14 (4):413-45.

8 Langford CP, Bowsher J, Maloney JP, Lillis PP. Social support: a conceptual analysis. J Adv Nurs 1997;25 (1):95-100.

9 Gottlieb BH, Bergen AE. Social support concepts and measures. J Psychosom Res 2010;69:511-20.

10 Shanafelt TD, West CP, Sloan JA, Novotny PJ, Poland GA, Menaker R, Rummans TA, Dyrbye LN. Career fit and burnout among academic faculty. Arch Intern Med 2009;169 (10):990-5.

11 Bakker AB, Demerouti E. The Job DemandsResources model: state of the art. J Manag Psychol 2007;22 (3):309-28.

12 Schaufeli WB, Bakker AB. Job demands, job resources, and their relationship with burnout and 
engagement: a multi-sample study. J Organ Behav 2004;25 (3):293-315.

13 Cohen S, Wills T. Stress, social support, and the buffering hypothesis. Psychol Bull 1985;98 (2):310-57.

14 Viswesvaran C, Sanchez JI, Fisher J. The role of social support in the process of work stress: a meta-analysis. J Vocat Behav 1999;54 (2):314-34.

15 Deelstra JT, Peeters MCW, Schaufeli WB, Stroebe W, Zijlstra FRH, van Doornen LP. Receiving instrumental support at work: when help is not welcome. $J$ Appl Psychol 2003;88 (2):324-31.

16 Halbesleben JRB. Sources of social support and burnout: a meta-analytic test of the conservation of resources model. J Appl Psychol 2006;91 (5):1134-45.

17 Sabel E, Archer J. "Medical education is the ugly duckling of the medical world" and other challenges to medical educators' identity construction: a qualitative study. Acad Med 2014;89 (11):1-7.

18 Madill A, Jordan A, Shirley C. Objectivity and reliability in qualitative analysis: realist, contextualist and radical constructionist epistemologies. Br J Psychol 2000;91 (1):1-20.

19 Bunniss S, Kelly DR. Research paradigms in medical education research. Med Educ 2010;44 (4):358-66.

20 Starks H, Trinidad SB. Choose your method: a comparison of phenomenology, discourse analysis, and grounded theory. Qual Health Res 2007;17 (10):1372-80.

21 Dowling M. From Husserl to van Manen. A review of different phenomenological approaches. Int J Nurs Stud 2007;44 (1):131-42.

22 Wojnar DM, Swanson KM. Phenomenology: an exploration. J Holist Nurs 2007;25 (3):172-80.

23 King N, Bravington A, Brooks J, Hardy B, Melvin J, Wilde D. The Pictor technique: a method for exploring the experience of collaborative working. Qual Health Res 2013;23 (8):1138-52.

24 Hardy B, King N, Firth J. Applying the Pictor technique to research interviews with people affected by advanced disease. Nurse Res 2012;20 (1):6-10.

25 King N. Using templates in the thematic analysis of text. In: Cassell C, Symon G, eds. Essential Guide to Qualitative Methods in Organizational Research. First. London: Sage Publications Ltd 2004;256-70.

26 van den Berg JW, Verberg CPM, Berkhout JJ, Lombarts MJMH, Scherpbier AJJA, Jaarsma ADC. A qualitative interview study on the positive well-being of medical school faculty in their teaching role: job demands, job resources and role interaction. BMC Res Notes 2015;8 (1):401.

27 Steinert Y, Macdonald ME, Boillat M, Elizov M, Meterissian S, Razack S, Ouellet M-N, McLeod PJ. Faculty development: if you build it, they will come. Med Educ 2010;44 (9):900-7.

28 Steinert Y. Faculty development: from workshops to communities of practice. Med Teach 2010;32 (5):4258.

29 O'Sullivan PS, Irby DM. Reframing research on faculty development. Acad Med 2011;86 (4):421-8.

30 Jippes E, Steinert Y, Pols J, Achterkamp MC, van Engelen JML, Brand PLP. How do social networks and faculty development courses affect clinical supervisors' adoption of a medical education innovation? An Exploratory Study. Acad Med 2013;88 (3):1-7.

31 Wenger E. Communities of Practice: Learning, Meaning, and Identity. Cambridge: Cambridge University Press 1998; 318p.

32 Akkerman S, Petter C, de Laat M. Organising communities-of-practice: facilitating emergence. $J$ Work Learn. 2008;20 (6):383-99.

33 Tims M, Bakker AB. Job crafting: towards a new model of individual job redesign. SA J Ind Psychol 2010;36 (2):1-9.

34 Ryan RM, Deci EL. Self-determination theory and the facilitation of intrinsic motivation, social development, and well-being. Am Psychol 2000;55 (1):68-78.

35 Taras V, Steel P, Kirkman BL. Improving national cultural indices using a longitudinal meta-analysis of Hofstede's dimensions. J World Bus 2012;47 (3):32941.

36 Tims M, Bakker AB, Derks D. The impact of job crafting on job demands, job resources, and wellbeing. J Occup Health Psychol 2013;18 (2):230-40.

37 Gordon HJ, Demerouti E, Le Blanc PM, Bipp T. Job crafting and performance of Dutch and American health care professionals. J Pers Psychol 2015;14 (4):192-202.

38 Sambunjak D, Straus SE, Marušić A. Mentoring in academic medicine. JAMA 2006;296 (9):1103.

39 Morelli SA, Lee IA, Arnn ME, Zaki J. Emotional and instrumental support provision interact to predict well-being. Emotion 2015;15 (4):484-93.

Received 24 February 2016; editorial comments to author 25 April 2016, 21 June 2016; accepted for publication 27 July 2016 